\title{
A Comparative Study of Unimodal and Multimodal Interactions for Digital TV Remote Control Mobile Application among Elderly
}

\author{
Nor Azman Ismail ${ }^{1}$ \\ Nur Haliza Abdul Wahab ${ }^{3}$ \\ School of Computing, Faculty of \\ Engineering, Universiti Teknologi \\ Malaysia, Johor Bahru, Malaysia
}

\author{
Nurul Aiman Ab Majid² \\ User Experience (UX) Department \\ Software R\&D Division \\ Sony EMCS (Malaysia) Sdn. Bhd
}

\author{
Farhan Mohamed ${ }^{4}$ \\ Media and Games Innovation Centre \\ of Excellence (MaGICX) \\ Universiti Teknologi Malaysia \\ Johor Bahru, Malaysia
}

\begin{abstract}
A research was conducted to study user interactions design for the TV remote control applications that are preferable among the elderly. Now-a-days smart home concept is widely accepted around the globe. Many applications were developed based on smart home concepts, such as smart remote-control applications for TVs and air conditioners. These applications were helpful in our daily life. However, the elderly tends not to use these applications because of the complexity of the processes and interaction design that is unfriendly. Therefore, this study was conducted to determine which interaction design is preferable for the elderly, enhancing the elderly experience in using the TV remote control application besides encouraging them to use one in daily life and keep up with new technologies. In this paper, the two types of new interaction designs - a touch-based only (unimodal) interaction and multimodal interaction prototypes and an existing TV Remote Control application were compared by conducting usability testing of these three applications on the elderly. Three parameters were considered to compare these three interaction designs: task completion time, error rate, and satisfaction. Also, using usability testing's data collection, statistical analysis was conducted to find out which type of interaction is preferable by the elderly. Ten elderlies participated in the usability testing carried out. The results show a significant difference in these three interactions designs regarding task completion time and satisfaction, but not error rate. After considering usability testing and analyses conducted, the elderly prefers a unimodal interaction design in the TV Remote Control application. Nevertheless, the unimodal interaction was not the typical “tapping buttons" user interface in existing applications. Instead, the favourable interaction design was the one that involved swiping gestures to replace several features that were implemented using buttons on existing TV remote control applications.
\end{abstract} elderly

Keywords-HCI; usability testing; unimodal; multimodal;

\section{INTRODUCTION}

Life is all about improvising and making things a lot better and easier than yesterday. Thus, since introducing the first desktop PC in the 1960s, people have developed different styles and ways to interact. Later, when smartphones were introduced to the public, the same thing happened. Nowadays, through the "Smart Home" concept, smartphones had become a powerful device that can control almost everything. One of the most common smartphone applications in the "Smart Home" domain is the remote-control application (app), such as the air-conditioner remote control app and TV remote control app. All the applications provided by this Smart Home remotecontrol apps make life easier, saving money and cost and save jobs time. However, besides all the superiority given, there is still a lack of Smart Home apps that can cater elderly's special needs, or in other words, elderly friendly. Research in HumanComputer Interaction (HCI) is meant for humans to find and study a better UI to enhance user experience [1].

All the above issues have motivated this study to determine which interaction design is preferable for the elderly in using the TV remote control application. This HCI research focused on enhancing elderly people's experience in using the TV remote control app on smartphones by testing out two types of a new set of interaction designs - touch-based only (unimodal) and multimodal interactions to simplify the user interaction and encourage the elderly to use the application. A usability study was then executed for each proposed solution and an existing system as the benchmark to determine which one was preferred by the elderly - the unimodal, gesture-based only interaction or its multimodal counterpart. Then, the collected data were analysed using statistical Analysis of Variance (ANOVA) tests and paired T-tests to find out where the significant difference arises between those three tested interaction designs.

The contribution of the work reported here is summarized as follows.

1) This study provides a possible solution to enhance the elderly's experience in using TV remote control applications with preferred user interaction design. This will further encourage them to use the latest technology and break down the social exclusion walls besides making their daily lives easier without the need to face the complicated user interface available on existing applications.

2) Proposing an elderly-friendly user interaction design for remote control applications will decrease the need for the elderly to rely on the physical remote control that has many reoccurring problems. Examples of these problems are cannot clearly see buttons on the remote control due to poor eyesight 
and confused which button on the remote control should be pressed to do some action as there are too many buttons on the remote control.

3) The outcome of this study can raise awareness of the importance of designing a specialized user interface for elderly people.

\section{RELATED WORKS}

According to United Nations (UN), elderly people are defined as people aged 60 and above. World Health Organization (WHO) also uses the 60 years old as a cut off for categorizing elderly or older persons, supporting the UN's definition [2]. In recent years, the percentage of the elderly people population has increased drastically worldwide [3]. Researchers in [4] stated that the European Union (EU) is now the world's oldest region, with $16 \%$ of its population comprised of people aged more than 64 years old. This fact is further proven in China, whereas China is the only nation with over 100 million ageing populations [5, 6]. In Malaysia, statistics from the Malaysian Communications and Multimedia Commission (MCMC) state that smartphone usage of people ranged between 60 to 64 years old had increased from 1.9 to 2.9\% in 2012 until 2014, respectively [7].

Furthermore, Nielsen stated that today's elderly people tend to have a dynamic lifestyle and most of the time, they are interested in modern technology, including in smartphone usage [6]. Statement in [8] shows that around 30\% of elderly own smartphones meet the 11-emerging discussion in [9] that commonly mentions that everyone in this world owns a smartphone. Thus, the rise in figures calls for a need to cater to elderly people's demand for a better user experience, especially in terms of the device itself and the interaction with the applications installed in it. This demand surfaced as elderly people have lower physical and mental capabilities than younger people [10]. Examples of these capabilities are sight, hearing, and motor abilities. These capabilities will go on degrading as people keep on getting older. As per all points stated above, a Mobile Application User Interface (UI) that seems "fit-for-all" is unsuitable for elderly people.

Mobile apps UI is graphical and usually touch-sensitivity on a device to permit communication and interaction between other devices. Mobile app UI, especially for the elderly, need to be designed to be user-friendly and easy to use to motivate the adoption of the technology [11].

Generally, the existing standard applications' UI is not user-friendly to elderly people in some ways. The author in [12] addressed that most smartphone UI is designed for youngsters and professional groups, which cause for elderly to struggle in learning and use their smartphones.

As the solution for these needs and requirements of the elderly, some previous studies found out that the elderly prefer applications with uncluttered, straightforward UI [13]. For instance, it is understandable that older people with poor vision might find it is challenging to read text displayed on the screen and recognize which button is for which action. Many types of research focused on this issue from various angles and managed to come out with several solutions on designing better user interaction for the elderly. Mobile design guidelines, UI principles, mobile health guidelines, inclusive design guidelines, and many others are referred to be summaries on to design the elements for the Mobile apps' UI [11].

The 4th Industrial Revolution (4IR) era has broad the Smart Home concept into a reality, though it is still a lack of friendly usage to the elderly [14]. The lack of elderly-friendly Smart Home applications hinders the elderly to keep up to date with the latest technology, thus widening the social gap with younger people. The cause of this problem may be due to the complexity of the features offered by the application itself to control smart devices effectively [15].

One of the most used Smart Home applications, remote control app, complexity arises from its features to support remote buttons. The need to support an extensive number of remote buttons leads to a complicated user interface and confuses elderly people [16]. Some of those buttons may not even be used by them. Also, most of these applications implemented a unimodal interaction design which involves tapping buttons as inputs. This type of interaction is indeed the simplest form of interaction. However, considering the vast number of remote buttons will confuse users, especially the elderly, on which button should be pressed for each feature. As a result, elderly people may opt not to use this application and still use traditional physical remote control. This too is a loss for the elderly as they need to keep on bearing typical problems when using the physical remote control, such as cannot see the remote buttons clearly due to degraded sight, misplacing the remote control.

Research by [17] combine voice commands, non-verbal behaviours, and gestures in their work. The result shows that natural interaction is more required if compared to remote control based on smartphones. The author in [18] provides a review and analysis of multimodal navigation solutions aimed at people with visual impairments. Both $[17,18]$ shows that it is important to understand how UI is suitable for the elderly. Thus, in this paper, a comparative study in Unimodal and Multimodal interactions for Digital TV Remote Control Mobile Application among the Elderly will be discussed.

\section{Methodology}

The evaluation of the proposed unimodal and multimodal interaction designs was conducted in three phases. The first phase was usability testing, where participants need to carry out a set of the same tasks on three different digital TV remote application interactions. One of the applications was the existing application, LG TV Remote, while the other two applications were the prototype built for each proposed interaction design, respectively. During the testing, the task error rate and time taken to complete each task for each participant was noted down. Besides, each participant was required to fill in the System Usability Survey (SUS) questionnaire for each interaction design tested and a Post-Test Questionnaire to compare participants' preferences between the two proposed interaction designs. Next, the second phase was User Preference Analysis. During this phase, the Post-Test Questionnaire results from all participants were analysed to know which participants and why they preferred interaction design. Finally, the Statistical Analysis using the Analysis of 
Variance (ANOVA) was carried out to analyse the collected data during the usability testing.

\section{A. Usability Testing}

To carry out the usability testing, both independent variables and dependent variables need to be determined. Independent variables are conditions that this research manipulated to assess their effects on participants' behaviours and performance. In contrast, dependent variables are parameters that responded to the manipulation of independent variables. A total of ten participants were gathered for the usability testing experiment conducted. Despite the small sample size $(\mathrm{N}=10)$, it was comparable and in line with published studies that recommended a baseline of 5-10 participants for usability studies [19].

Most of the participants are elderly residents from Kampung Jalan Kebun, Shah Alam. Fig. 1 shows usability testing conducted on one of the participants of this testing.
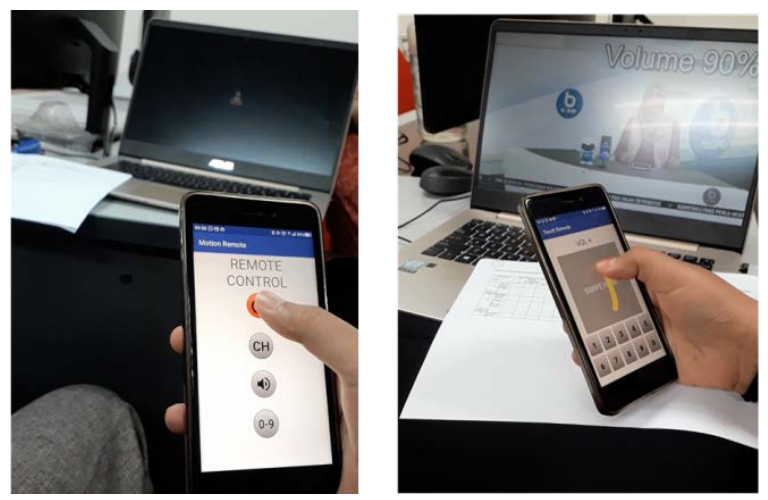

Fig. 1. Usability Testing.

1) Independent variables: There were three independent variables manipulated in this research that closely related to the proposed interaction designs for a TV remote control application. These three independent variables were:

a) Existing TV remote control application (shown in Fig. 2).

b) TV remote control prototype with the proposed touch gestures interaction (unimodal) only (shown in Fig. 3).

c) TV remote control application prototype with the proposed multimodal interaction (shown in Fig. 4).

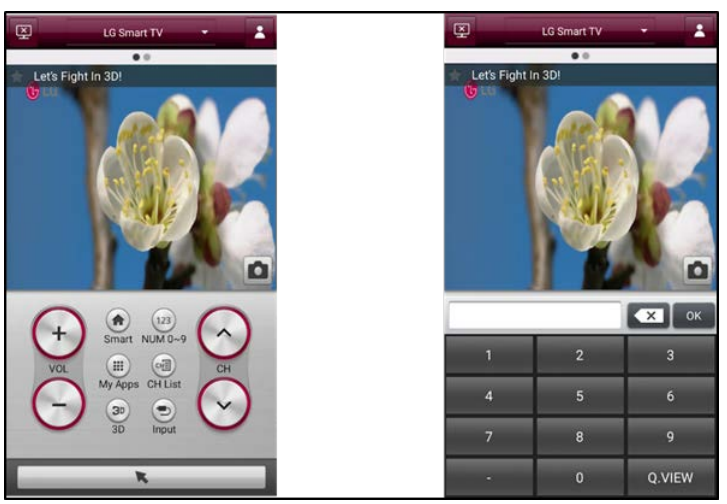

Fig. 2. LG TV Remote App user Interface. [13].

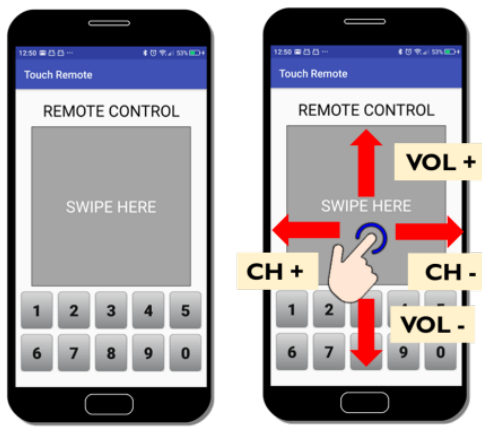

Fig. 3. Proposed unimodal (Solution 1) user Interface.

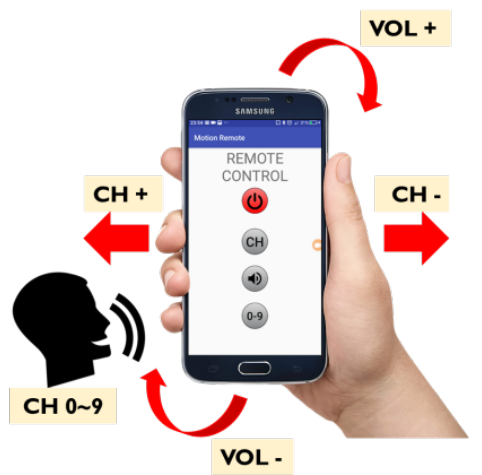

Fig. 4. Proposed Multimodal (Solution 2) user Interface.

2) Dependent variables: The dependent variables, also known as evaluation metrics, captured by this usability testing were effectiveness (error rate), efficiency (task completion time) and satisfaction.

According to [20], effectiveness is universally recognized as an essential usability metric. The participants' error rate measured the effectiveness metrics in this research. A user error was considered to happen when the participant made a mistake that diverted from the task assigned [20]. For example, a task was given to the participant to increase the volume of the TV. However, the participant mistakenly decreases the TV volume thus needed to redo the task assigned until completed. The error rate of participant $\mathrm{j}$ for task $\mathrm{i}$ can be calculated as the total of user error(s) made by participant $\mathrm{j}$ for task $\mathrm{i}$, as shown in Equation 1 [21].

Error Rate, error $_{i j}=\sum$ (user error made $)$

Next, to measure the efficiency of the task, the time taken for participants to complete the task need to be calculated [22]. Equation 2 below showed the formula to calculate the task completion time of participant $\mathrm{j}$ for task $i, t_{i j}$ [23].

Task $_{i}$ Completion Time, $t_{i j}=$ End Time - Start Time

Finally, according to [24], satisfaction can be defined as user acceptance and contentment levels experienced by participants. The satisfaction metric in this research was measured using the System Usability Scale (SUS), a 10question long survey aiming to quantify the usability of the developed TV remote control app prototypes with the proposed interaction designs. 
The SUS score can be calculated using the formula depicted in Equation 3 [25]. In the equation, $\sum$ OddQ referred to the summation of points from odd-numbered questions while $\sum$ EvenQ referred summation of points from evennumbered questions.

$$
\text { SUS Score }=\left(\left(\sum \text { OddQ }-5\right)+\left(25-\sum \text { Even } Q\right)\right) \times 2.5
$$

\section{B. User Preference Analysis}

The user preference analysis was conducted using a PostTest Questionnaire to determine which interaction designs are more preferred by the elderly - touch gestures-only or multimodal approach and the reasons behind it. The Post-Test Questionnaire was given to participants after they completed the usability testing for both prototypes. This questionnaire consisted of nine questions, and its scoring was designed based on a 7-point Likert Scale to analyse the more favoured prototype by each participant, respectively. Table I shows the list of the Post-Test Questionnaire questions list.

\section{Statistical Analysis using ANOVA}

To compare the usability of the three different interaction designs, the data gathered during the usability testing needed to be analysed to confirm the relationship between the independent and dependent variables chosen. This analysis was conducted using the one-way Analysis of Variance (ANOVA) with repeated measures and an equal sample size. The ANOVA with repeated measures was applied to evaluate the effects of different conditions (independent variables): existing user interface, proposed touch-based only interaction, and proposed multimodal interaction, on efficiency (task completion time), effectiveness (error rate), and satisfaction.

For each ANOVA analysis carried out, a set of a null hypothesis and alternate hypothesis was established. Therefore, in total, there were three sets of hypotheses tested, as shown in Table II.

TABLE I. POST-TEST QUESTIONNAIRE’S QUESTION LIST

\begin{tabular}{|l|l|}
\hline $\begin{array}{l}\text { Question } \\
\text { Number }\end{array}$ & Post-Test Questionnaire Question \\
\hline 1 & Which interaction design will you prefer to use in the future? \\
\hline 2 & Which interaction design did you find complex? \\
\hline 3 & Which interaction design did your find easier to use? \\
\hline 4 & Which interaction design would you need the help with to use? \\
\hline 5 & $\begin{array}{l}\text { Which interaction design did you find more intuitive to control } \\
\text { a TV? }\end{array}$ \\
\hline 6 & Which interaction design is most accurate? \\
\hline 7 & $\begin{array}{l}\text { Which interaction design do you think people would learn to } \\
\text { use quicker? }\end{array}$ \\
\hline 8 & $\begin{array}{l}\text { Which interaction design did you find more cumbersome to } \\
\text { use? }\end{array}$ \\
\hline 9 & Which interaction design did you feel more confident using? \\
\hline
\end{tabular}

TABLE II. HYPOTHESES USED IN ANOVA ANALYSES

\begin{tabular}{|l|l|l|}
\hline Metric & Hypothesis & Hypothesis Description \\
\hline $\begin{array}{l}\text { Time taken } \\
\text { to complete } \\
\text { (efficiency) }\end{array}$ & H1 ${ }_{0}$ & $\begin{array}{l}\text { There is no difference in the user's } \\
\text { efficiency in controlling the TV using an } \\
\text { application with the existing interface, } \\
\text { proposed touch-based gestures interface } \\
\text { and proposed multimodal interface. }\end{array}$ \\
\cline { 2 - 3 } & H1 $1_{1}$ & $\begin{array}{l}\text { There is a difference in user's efficiency in } \\
\text { at least one of the interfaces tested. }\end{array}$ \\
\hline \multirow{5}{*}{ Error rate } & $\mathrm{H} 2_{0}$ & $\begin{array}{l}\text { There is no difference in the user's error } \\
\text { rate in controlling the TV using an } \\
\text { application with the existing interface, } \\
\text { proposed touch-based gestures interface } \\
\text { and proposed multimodal interface. }\end{array}$ \\
\cline { 2 - 3 } & $\mathrm{H} 2_{1}$ & $\begin{array}{l}\text { There is a difference in the user's error rate } \\
\text { in at least one of the interfaces tested. }\end{array}$ \\
\hline \multirow{5}{*}{ Satisfaction } & $\mathrm{H} 3_{0}$ & $\begin{array}{l}\text { There is no difference in user's satisfaction } \\
\text { in controlling the TV using an application } \\
\text { with the existing interface, proposed touch- } \\
\text { based gestures interface and proposed } \\
\text { multimodal interface. }\end{array}$ \\
\cline { 2 - 3 } & $\mathrm{H} 3_{1}$ & $\begin{array}{l}\text { There is a difference in user's satisfaction } \\
\text { in at least one of the interfaces tested. }\end{array}$ \\
\hline
\end{tabular}

\section{RESULTS AND ANALYSIS}

This part focused on evaluating the usability of the two proposed interactions dialogue designed. The evaluation was carried out with the latest and most stable version of the prototypes, together with an existing application, LG Remote TV [13], to serve as a benchmark. Firstly, the collected data on ten participants aged at least 50 years old and above were analysed to understand their background and experiences. Next, the usability testing results were described, tabulated, and illustrated in graphs. Furthermore, analysis was conducted in two ways i) user preference analysis to study which proposed user interaction designs were preferable by elderly and, ii) the statistical analysis using ANOVA on three different metrics measured on three different interaction designs (existing application and the two proposed designs) to find out is there any significant difference between them.

\section{A. Task Completion Time (Efficiency)}

Table III shows the means and standard deviations of task completion times for all participants, and these data were described in Fig. 5. For each user interaction design, participants were required to complete a set of identical five tasks. Participants were requested to carry out tasks $1 \mathrm{~A}$ to $5 \mathrm{~A}$ on the existing application, tasks $1 \mathrm{~B}$ to $5 \mathrm{~B}$ on proposed Solution 1, and tasks 1C to 5C on proposed Solution 2.

Based on Table III and Fig. 2, it was deduced that for each user interaction design, the task that took the least average time to complete was task $1 \mathrm{~A}, 5 \mathrm{~B}$, and $5 \mathrm{C}$, respectively, which were tasks to turn on the TV (for existing application) and task to turn off the TV (for both proposed design). Overall, on average, participants took the shortest time to turn off the TV using proposed Solution 1, which took 1.6 seconds, followed by proposed Solution 2 with 1.7 seconds. On the other hand, the task that took the longest time to complete was task $2 \mathrm{~A}$, to change the channel to "TV3" using the existing application, 
with an average of 12.8 seconds. The same task carried out for the two proposed solutions 1 , task $2 \mathrm{~B}$, managed to significantly reduce the average time taken by approximately one fifth to 2.2 seconds only.

On average, participants spent the longest time to complete the tasks list when using the existing application, LG TV Remote, with an average of 31.15 seconds. In contrast, the proposed Solution 1 interaction design allowed participants to complete all the tasks fastest with an average time of 15.74 seconds. The proposed multimodal interaction (Solution 2) came in second fasted with a total average of 22.96 seconds.

\section{B. Error Rate (Effectiveness)}

In this study, the error rate was calculated based on the number of errors participants made per task. The means and standard deviations for participants' error rate of each task for all participants $(n=10)$ were shown in Table IV. At the same time, Fig. 6 illustrates the total number of errors made by all participants, categorized by the type of interaction design used.

TABLE III. MEANS \& STANDARD DEVIATIONS FOR TASK COMPLETION TIME OF EACH TASK FOR ALL PARTICIPANTS

\begin{tabular}{|l|l|l|l|}
\hline Task & Description & $\begin{array}{l}\text { Mean, } \\
\overline{\boldsymbol{x}}\end{array}$ & $\begin{array}{l}\text { Standard } \\
\text { Deviation, } \boldsymbol{\sigma}\end{array}$ \\
\hline 1A & Turn on the TV (Existing app) & 2.5 & 1.714 \\
\hline 2A & Change channel to “TV3” & 12.8 & 4.368 \\
\hline 3A & Turn up volume & 5.6 & 2.383 \\
\hline 4A & Change to next two channels & 7.6 & 3.456 \\
\hline 5A & Turn off the TV & 2.7 & 0.465 \\
\hline 1B & Turn on the TV (Solution 1) & 2.3 & 1.217 \\
\hline 2B & Change channel to “TV3” & 2.2 & 0.660 \\
\hline 3B & Turn up volume & 2.9 & 1.119 \\
\hline 4B & Change to next two channels & 6.7 & 4.461 \\
\hline 5B & Turn off the TV & 1.6 & 0.663 \\
\hline 1C & Turn on the TV (Solution 2) & 2.5 & 1.852 \\
\hline 2C & Change channel to “TV3” & 5.1 & 2.110 \\
\hline 3C & Turn up volume & 4.8 & 2.114 \\
\hline 4C & Change to next two channels & 8.9 & 4.237 \\
\hline 5C & Turn off the TV & 1.7 & 0.962 \\
\hline
\end{tabular}

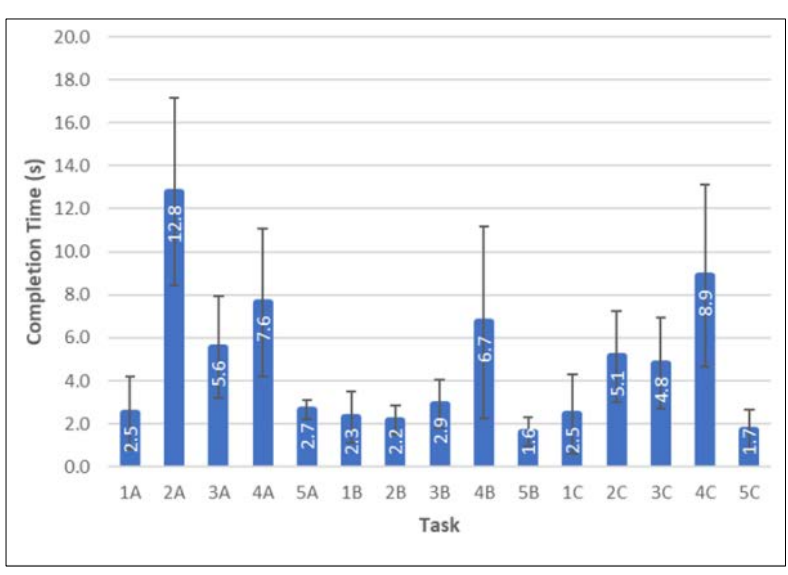

Fig. 5. Participants' Task Completion Time Average for each Task.
TABLE IV. MEANS \& STANDARD DEVIATIONS FOR PARTICIPANTS' ERROR RATE OF EACH TASK

\begin{tabular}{|l|l|l|l|}
\hline Task & Description & $\begin{array}{l}\text { Mean, } \\
\overline{\boldsymbol{x}}\end{array}$ & $\begin{array}{l}\text { Standard } \\
\text { Deviation, } \boldsymbol{\sigma}\end{array}$ \\
\hline 1A & Turn on the TV (Existing app) & 0.0 & 0.000 \\
\hline 2A & Change channel to “TV3” & 0.7 & 1.059 \\
\hline 3A & Turn up volume & 0.2 & 0.422 \\
\hline 4A & Change to next two channels & 0.2 & 0.632 \\
\hline 5A & Turn off the TV & 0.2 & 0.422 \\
\hline 1B & Turn on the TV (Solution 1) & 0.0 & 0.000 \\
\hline 2B & Change channel to “TV3” & 0.1 & 0.316 \\
\hline 3B & Turn up volume & 0.0 & 0.000 \\
\hline 4B & Change to next two channels & 0.1 & 0.316 \\
\hline 5B & Turn off the TV & 0.3 & 0.675 \\
\hline 1C & Turn on the TV (Solution 2) & 0.0 & 0.000 \\
\hline 2C & Change channel to “TV3” & 0.0 & 0.000 \\
\hline 3C & Turn up volume & 0.5 & 0.707 \\
\hline 4C & Change to next two channels & 0.1 & 0.316 \\
\hline 5C & Turn off the TV & 0.0 & 0.000 \\
\hline
\end{tabular}

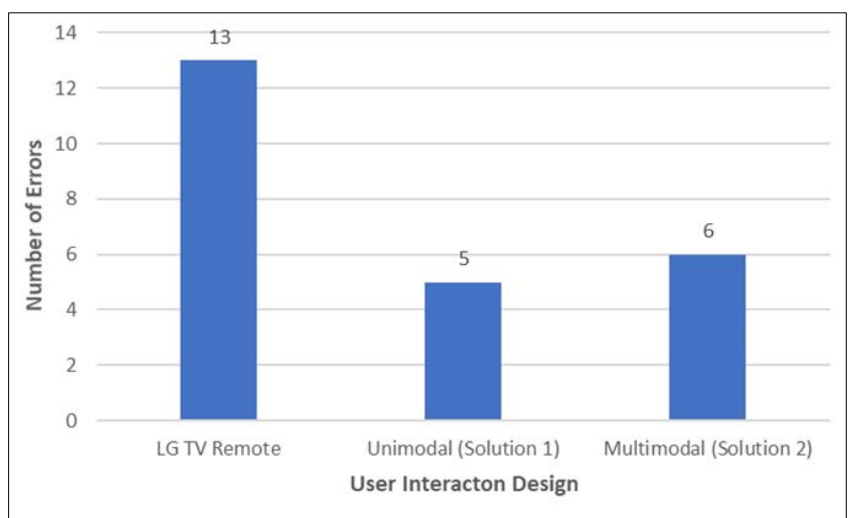

Fig. 6. The Total Number of Errors made for each Interaction Design.

A total of 13 errors were made by all participants when using the existing application, which was the most number among the three interaction designs. The least total number of errors made was from the proposed unimodal interaction design (unimodal). Five errors were made in total, which was more than half of the errors made when using the existing application. Next, followed closely in second, was the proposed multimodal interaction, with a total of six errors made.

\section{Satisfaction}

The satisfaction of participants was measured based on the SUS for each interaction design used in the usability testing. SUS is a 10-question survey to measure participants' satisfaction with the system, or in this case, interaction design tested. A higher total score equals higher satisfaction. An interaction design with good usability should score at least 70 and above [20]. Upon finishing a specific interaction design test, participants were requested to fill in the SUS for that interaction design. Thus, in total, each participant needed to fill in three SUS forms. 


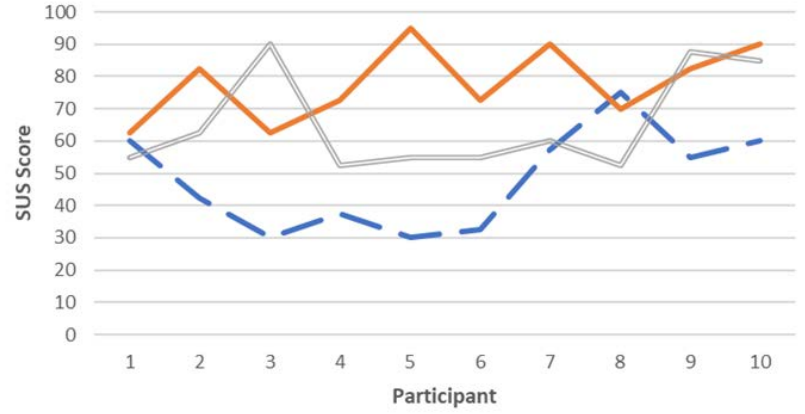

- LG TV Remote —Unimodal (Solution 1) Multimodal (Solution 2)

Fig. 7. Line chart of Participant Individual SUS Scoring for each Interaction Design.

Fig. 7 draws a line graph based on the individual SUS score for the three interaction designs of all participants. Based on Fig. 7, the lowest score, 30, was given by two participants for the existing system interaction design. On the other hand, a participant had given the highest SUS score in this research, 95, for the proposed unimodal interaction (Solution 1).

Most of the participants $(n=7)$ preferred Solution 1 the most. Two out of three remaining participants $(n=2)$ inclined towards multimodal interaction design (Solution 2), while the remaining one participant $(\mathrm{n}=1)$ opted for the existing system as her top choice.

Fig. 8 shows the average SUS score given by all participants $(n=10)$ for each interaction design. The proposed unimodal interaction design (Solution 1) has the highest average SUS score, 78.0, compared to the other two. The second highest interaction design with an average SUS score of 65.5 was the proposed multimodal interaction design, followed by the existing LG TV Remote application with a 48.0 score. Based on these average scores, in general, it can be deduced that only the proposed unimodal interaction design (Solution 1) has good usability.

\section{User Preference Analysis}

After carrying out the designated set of tasks for all three interaction designs, participants need to answer a Post-Test Questionnaire to understand the reasons behind their preferences between the two proposed solutions. The Post-Test Questionnaire consisted of 9 questions, whereas participants need to score them between one and seven. The lower score given means that a particular participant favoured the proposed unimodal interaction design (Solution 1) more, while the higher score was given in favour of multimodal interaction design (Solution 2). A score in the middle range (i.e., four) means participants could not decide their inclination towards which interactions related to that question.

Fig. 9 illustrated the average score given by all participants for each questionnaire's question. Based on the average scores, the proposed unimodal interaction design was highly preferred by participants in terms of future usage (Question $1, \bar{x}_{\text {score }}=$ 2.9 ), easiness to use (Question $3, \bar{x}_{\text {score }}=2.8$ ), interaction design accuracy (Question 6, $\bar{x}_{\text {score }}=2.5$ ), learnability (Question 7, $\bar{x}_{\text {score }}=2.7$ ), and confidence in usage (Question 9, $\bar{x}_{\text {score }}=2.8$ ).

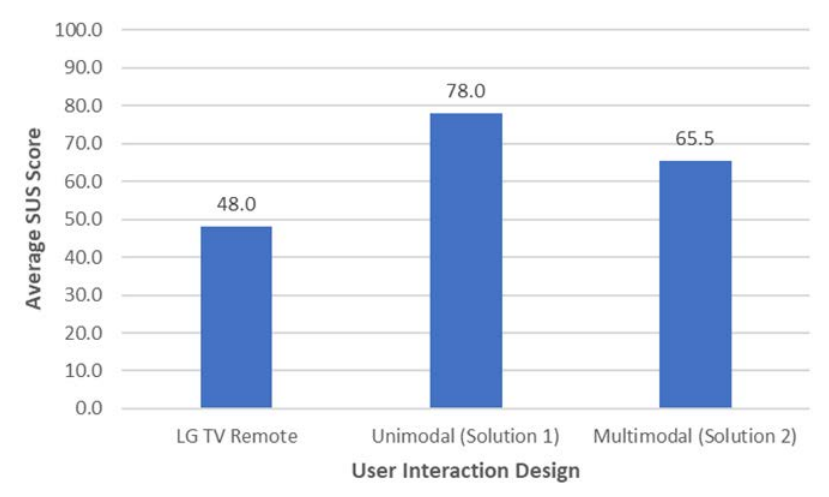

Fig. 8. Average SUS Scoring for each Interaction Design.

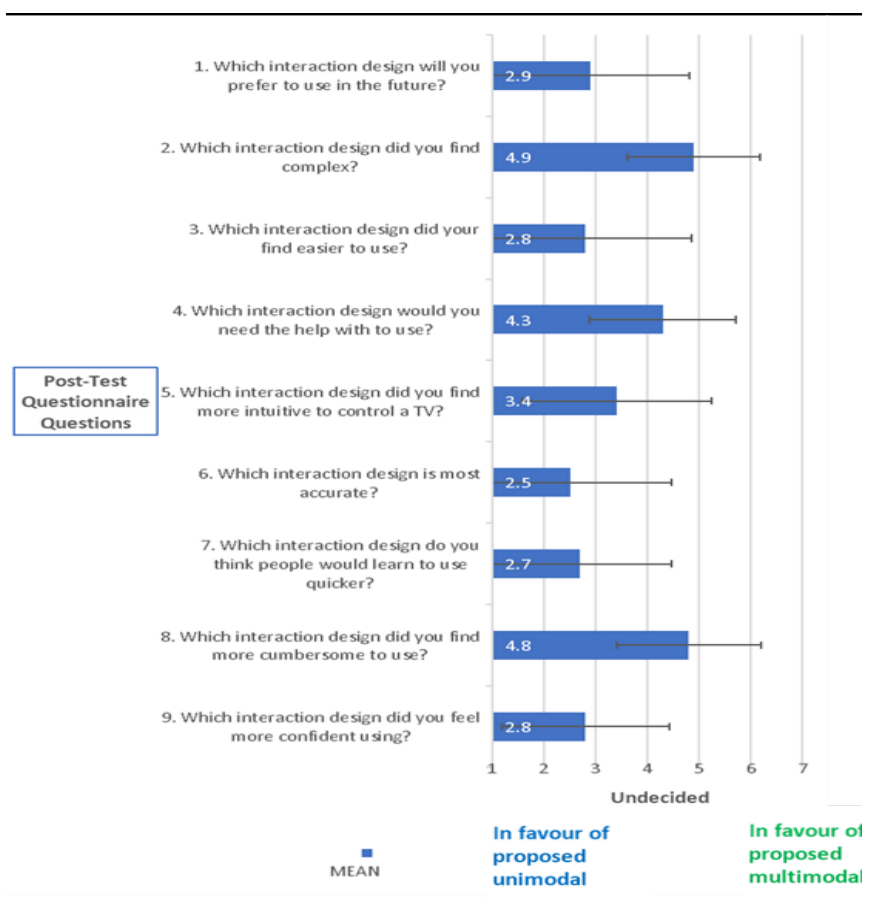

Fig. 9. Average Post-Test Questionnaire score given by All Participants.

\section{E. Statistical Analysis using ANOVA}

ANOVA statistical analyses with a confidence level of $95 \%$ were carried out to justify rejecting or accepting the previously defined set of hypotheses in part II [26]. ANOVA was used as the significance test needed to be carried out on three different TV Remote Control interaction designs - the existing application, the proposed unimodal interaction, and the proposed multimodal interaction. A total of three ANOVA analyses were conducted, each for task completion time (efficiency), error rate (effectiveness) and satisfaction.

If the null hypothesis for an ANOVA test conducted was rejected, a post hoc analysis was carried out to have in-depth perspectives on which interaction design(s) had a significant difference from other interaction design(s). In this case, the Bonferroni corrected alpha was used to compare against the pvalues conducted on the post hoc analysis. This corrected alpha value was used to account for the error rate that may be increased when carrying out multiple t-tests. The formula for the Bonferroni corrected alpha, $\alpha_{\text {corrected }}$, was shown in 
Equation 4 [24]. $\alpha$ in the below equation stands for the original alpha value used in this experiment which is equivalent to 0.05 .

$\alpha_{\text {corrected }}=\frac{\alpha}{\text { number of tests performed }}$

1) Comparison between the different interaction designs in controlling TV efficiency: The ANOVA analysis was conducted to justify any significant difference in task completion time taken (efficiency) between the three different interaction designs. Table $V$ showed the descriptive statistics of task completion time for each interaction design. On average, participants took the least time when using the proposed Solution 1 (15.74s), followed by Solution 2 (22.96s), and finally the existing application (31.15s). The variance of each value was then calculated and further down used to carry out the ANOVA analysis.

The ANOVA analysis conducted revealed that the p-value of this test was $4.745 \times 10^{-5}$. As the p-value is less than the alpha value used for this test ( $\alpha=0.05$ ), the null hypothesis, $\mathrm{H} 1_{0}$, "there is no difference in user's efficiency in controlling the TV using an application with the existing interface, proposed touch-based gestures interface and proposed multimodal interface", was rejected. Instead, the alternative hypothesis, $\mathrm{H} 1_{1}$, "there is a difference in user's efficiency in at least one of the interfaces tested", was accepted.

As the null hypothesis, $\mathrm{H} 1_{0}$ was rejected, a post hoc analysis was then carried out to determine which user interaction design has different efficiency. For this post hoc analysis, the $\alpha_{\text {corrected }}$ used was 0.0167 ( $\alpha=0.05$ divided by 3 tests). Based on the T-tests conducted, there were significant differences in user's efficiency between when using the existing application and using the proposed Solution 1 $\left(p-\right.$ value $\left.=6.380 \times 10^{-5}<\alpha_{\text {corrected }}\right)$, and between using the proposed Solution 1 and using the proposed Solution $2\left(p-\right.$ value $\left.=0.0107<\alpha_{\text {corrected }}\right)$. However, there was no significant difference in user efficiency between using the existing application and using the proposed Solution 2 $\left(p-\right.$ value $\left.=0.0172>\alpha_{\text {corrected }}\right)$.

2) Comparison between the different interaction designs in controlling tv effectiveness: Next, ANOVA analysis was carried out to test the existence of significant differences in the mean of error rate (effectiveness) between the three interaction designs - existing application, proposed unimodal, touch-based only (Solution 1) and proposed multimodal interaction. The descriptive statistics of the error rate for these three interaction designs were tabulated in Table VI.

The results of the ANOVA test conducted showed that there was no significant difference in error rate (effectiveness) between these three interaction designs. The p-value for this test was 0.285 , which was greater than the alpha value, 0.05 $(p-$ value $>\alpha)$. Therefore, the null hypothesis for this test, $\mathrm{H} 2_{0}$, "there is no difference in user's error rate in controlling the TV using an application with the existing interface, proposed touch-based gestures interface and proposed multimodal interface”, was accepted.
3) Comparison between the different interaction designs in controlling tv user's satisfaction: Finally, statistical analysis using ANOVA was conducted to determine any significant difference in participants' satisfaction when using three different user interaction designs of the TV Remote Control application. The descriptive statistics of participants' satisfaction when using the three different user interaction designs were shown in Table VII.

The results of the ANOVA analysis were conducted for participants' satisfaction with an existing application. Solution 1 and Solution 2 indicated a significant difference in participants' satisfaction with the three different user interaction designs. The p-value of this ANOVA analysis was 0.000323 , lesser than the alpha value, $\alpha$, which was 0.05 $(p-$ value $<\alpha)$. Therefore, the null hypothesis for this ANOVA testing, $\mathrm{H}_{0}$, "there is no difference in user's satisfaction in controlling the TV using an application with the existing interface, proposed touch-based gestures interface and proposed multimodal interface", was rejected. Instead, it was concluded that the alternative hypothesis, $\mathrm{H}_{3}$, "there is a difference in user's satisfaction in at least one of the interfaces tested”, was accepted.

TABLE V. DESCRIPTIVE STATISTICS OF TASK COMPLETION TIME FOR EXISTING APP, SOLUTION 1 AND SOLUTION 2

\begin{tabular}{|l|l|l|l|l|}
\hline Interaction Design & $\mathbf{n}$ & Sum, $\boldsymbol{\Sigma}$ & Mean, $\overline{\boldsymbol{x}}$ & $\begin{array}{l}\text { Variance, } \\
\boldsymbol{\sigma}^{\mathbf{2}}\end{array}$ \\
\hline Existing app & 10 & 311.5 & 31.15 & 57.689 \\
\hline $\begin{array}{l}\text { Proposed touch-based, } \\
\text { unimodal gestures } \\
\text { (Solution 1) }\end{array}$ & 10 & 157.4 & 15.74 & 24.967 \\
\hline $\begin{array}{l}\text { Proposed multimodal } \\
\text { gestures (Solution 2) }\end{array}$ & 10 & 229.6 & 22.96 & 38.465 \\
\hline
\end{tabular}

TABLE VI. DESCRIPTIVE STATISTICS OF ERROR RATE FOR EXISTING APP, SOLUTION 1 AND SOLUTION 2

\begin{tabular}{|l|l|l|l|l|}
\hline Interaction Design & $\mathbf{n}$ & Sum, $\boldsymbol{\Sigma}$ & Mean, $\overline{\boldsymbol{x}}$ & $\begin{array}{l}\text { Variance, } \\
\boldsymbol{\sigma}^{\mathbf{2}}\end{array}$ \\
\hline Existing app & 10 & 13 & 1.30 & 2.900 \\
\hline $\begin{array}{l}\text { Proposed touch-based, } \\
\text { unimodal gestures } \\
\text { (Solution 1) }\end{array}$ & 10 & 5 & 0.50 & 0.944 \\
\hline $\begin{array}{l}\text { Proposed multimodal } \\
\text { gestures (Solution 2) }\end{array}$ & 10 & 6 & 0.60 & 0.489 \\
\hline
\end{tabular}

TABLE VII. DESCRIPTIVE STATISTICS OF SATISFACTION FOR EXISTING APP, SOLUTION 1 AND SOLUTION 2

\begin{tabular}{|l|l|l|l|l|}
\hline Interaction Design & $\mathbf{n}$ & Sum, $\boldsymbol{\Sigma}$ & Mean, $\overline{\boldsymbol{x}}$ & $\begin{array}{l}\text { Variance, } \\
\boldsymbol{\sigma}^{\mathbf{2}}\end{array}$ \\
\hline Existing app & 10 & 480 & 48.00 & 242.778 \\
\hline $\begin{array}{l}\text { Proposed touch-based, } \\
\text { unimodal gestures } \\
\text { (Solution 1) }\end{array}$ & 10 & 780 & 78.00 & 135.833 \\
\hline $\begin{array}{l}\text { Proposed multimodal } \\
\text { gestures (Solution 2) }\end{array}$ & 10 & 655 & 65.50 & 241.389 \\
\hline
\end{tabular}


To further study the ANOVA testing results, a post hoc analysis was conducted to understand which user interaction design(s) significantly differed in user satisfaction compared to another interaction design.

All the p-values from the additional tests (three t-tests) carried out were compared against the Bonferroni corrected alpha value $\left(\alpha_{\text {corrected }}=0.0167\right)$. Based on the posthoc analysis conducted, it was indicated that the significant difference only existed between the existing application and the proposed unimodal interaction design (Solution 1), with pvalue $0.000142, \quad\left(p-\right.$ value $\left.=0.000142<\alpha_{\text {corrected }}\right)$. However, there were no significant differences in user's satisfaction between the existing application and proposed Solution $2\left(p-\right.$ value $\left.=0.0216>\alpha_{\text {corrected }}\right)$, and between the proposed Solution 1 and proposed Solution 2 ( $p-$ value $=$ $\left.0.0577>\alpha_{\text {corrected }}\right)$.

\section{Discussion}

The study observed three hypotheses of efficiency, error rate and satisfaction. Acceptance through the efficacy of the novel unimodal approach in $\mathrm{H} 1$ showed potential in improving elderly interaction requirements through new interaction designs, where at the same time, the $\mathrm{H} 2$ result showed that unimodal interaction is still the best solution in addressing elderly interaction requirements. While there is no significance found between unimodal and multimodal interaction in $\mathrm{H} 3$, further understanding of elderly cognitive load such as cognitive classification [27] could be further explored in designing multimodal interaction for the elderly.

\section{CONCLUSION}

Based on the results and analysis conducted, it was proven that participants had the best efficiency (tasks completion time) when controlling the TV using the proposed unimodal, touchbased only interaction design (Solution 1) than when using the existing system and the proposed multimodal (Solution 2). It was also noted that participants were more satisfied when using the proposed unimodal (Solution 1) than the existing system. However, there was no significant difference in user satisfaction between the proposed Solution 1 and the proposed Solution 2.

On the other hand, there was no significant difference in effectiveness (error rate) when using different interaction designs. Most participants did not make any human error when executing the designated tasks on either interaction design.

Therefore, the new set of unimodal interaction designs (touch-based only) was better than the other two interaction designs in terms of efficiency and produced better satisfaction than when using the existing system. Nevertheless, the unimodal interaction was not the typical "tapping buttons" user interface in existing applications. Instead, the favourable interaction design was the one that involved swiping gestures to replace several features that were implemented using buttons on existing TV remote control applications.

A few suggestions can be carried out in the future. First, this research can include elderly people in the design process of interactive dialogue for controlling TV using the TV remote control application. Finally, more in-depth research can be conducted to study elderly interaction design preference for the TV Remote Control application based on their health conditions (i.e., healthy elderly versus elderly with mild cognitive impairments). This is to study whether the elderly's health conditions affect the interaction design preferred or not.

\section{ACKNOWLEDGMENT}

Special thanks to Pusat Aktiviti Warga Emas Johor Bahru (PAWEJB) and elderly residents of Kampung Jalan Kebun, Shah Alam, for participating in the interview session and usability testing experiment conducted for this research. The authors also wish to thank the Ministry of Higher Education, Malaysia, for funding this study under the Fundamental Research Grant Scheme (FRGS/1/2019/ICT04/UTM/02/8).

REFERENCES
[1] Jiahao Wang, (2019). From Self-efficacy to Human-Computer Interaction Design, Journal of Physics: Conference Series 1168(3):032060, DOI: 10.1088/1742-6596/1168/3/032060.

[2] United Nations, Department of Economic and Social Affairs, Population Division (2019). World Population Ageing 2019: Highlights (ST/ESA/SER.A/430). The United Nations, ISBN: 978-92-1-148325-3, 2019.

[3] Xunjie Cheng,Yang Yang,David C. Schwebel,Zuyun Liu,Li Li,Peixia Cheng,Peishan Ning,Guoqing Hu, (2020). Population Ageing and Mortality During 1990-2017: A Global Decomposition Analysis. DOI: 10.1371/journal.pmed.1003138.

[4] Jonathan Cylus, Josep Figueras, Charles Normand, (2019). Will Population Ageing Spell The End of The Welfare State?: A review of evidence and policy options, World Health Organization (WHO).

[5] B. Jiang and D. Deng, (2016). The Research on Elderly-Adaptive Interface Design Based on Choice-Oriented Attention Theory, in Design, User Experience, and Usability: Design Thinking and Methods, vol. 1, pp. 293-303.

[6] Zhu, H., Lu, J., Zhang, Y. et al., (2019). Responses to Population Ageing in The New ERA: a national condition report from China”, China population devision stud. 2, 272-283. DOI: 10.1007/s42379-0180017-9.

[7] Aslina Baharum, Nurul Hidayah Mat Zain, Aryanto Taharudin, Rozita Hanapi, Azali Saudi and Rayner Alfred, (2017). "Guidelines of User Interface Design for Elderly Mobile Applications: A Preliminary Study”, Asian Journal of Information Technology 16 (1) Medwell Journal: 38-44.

[8] Muath Alhussain Khawaji, (2017). Overcoming challenges in Smart Phone use Among Older Adults in Saudi Arabia, Graduate Theses and Dissertations, IOWA State University Digital Repository.

[9] Gladden, D’Juan, (2018). The Effects of Smartphones on Social Lives: How They Affect Our Social Interactions and Attitudes, OTS. Master's Level Projects \& Papers. 586.

[10] McPhee, Jamie S et al. (2016). Physical activity in older age: perspectives for healthy ageing and frailty. Biogerontology vol. 17,3 (2016): 567-80. DOI:10.1007/s10522-016-9641-0.

[11] Khan Kalimullah, Donthula Sushmitha, (2017). “Influence of Design Elements in Mobile Applications on User Experience of Elderly People”, The $7^{\text {th }}$ International Conference on Current and Future Trends on Information and Communication Technologies in Healthcare, Procedia Computer Science 113, 352-359.

[12] Wong et. al., Rahimah Ibrahim, Tengku Aizan Hamid, Evi Indriasari Mansor, (2018). Mismatch between older adults' expectation and smartphone user interface, Malaysian Journal of Computing, 3(2): 138153.

[13] Kapczynski, Adrian \& Lawnik, Marcin. (2020). Initial survey on the interaction of elderly people with smartphones. Scientific Papers of Silesian University of Technology. Organization and Management Series. 303-313. DOI:10.29119/1641-3466.2020.149.26.

[14] Vaportzis, Eleftheria et al. (2017). Older Adults Perceptions of Technology and Barriers to Interacting with Tablet Computers: A Focus 
Group Study. Frontiers in psychology vol. 8: 1687. DOI:10.3389/fpsyg.2017.01687.

[15] Punchoojit Lumpapun, Hongwarittorrn Nuttanont, (2017). Usability Studies on Mobile User Interface Design Patterns: A Systematic Literature Review, Journal Advances in Human-Computer Interaction, DOI:10.1155/2017/6787504.

[16] Mithun Ahamed, (2021). Theory of Usability Index (TOUI) For Improving The Usability of Human-Computer Interaction Design", Thesis for: PhD in Information and Communication Technology, DOI: 10.13140/RG.2.2.18750.41280.

[17] Chiara Cogerino, Giovanni Rosso, Ilaria Bosi, Antonella Frisiello, Marco Bazzani, (2017). Multi-modal input devices for Active and Healthy Ageing, The $25^{\text {th }}$ International Conference on Software, Telecommunications and Computer Networks.

[18] Kuriakose, Bineeth, Raju Shrestha, and Frode E. Sandnes 2020. "Multimodal Navigation Systems for Users with Visual ImpairmentsA Review and Analysis” Multimodal Technologies and Interaction 4, no. 4: 73. DOI:10.3390/mti4040073.

[19] Macefield, R. (2009). How to specify the participant group size for usability studies: a practitioner's guide. Journal of Usability Studies, 5(1), 34-45.

[20] N. A. Ismail and Y. Y. Pang, (2015). A Multimodal Interaction for Map Navigation and Evaluation Study of its Usability, vol. 10, no. 23, pp. 17962-17970.
[21] Lee Son, T, Wesson, J., and Vogts, D., (2018). Designing a Natural User Interface to support information sharing among co-located mobile devices, South African Computer Journal 30(2), 44-71. DOI: 10.18489/sacj.v30i2.440.

[22] Jeff Sauro, James R. Lewis, (2016). Quantifying The User Experience: Practical Statistics For User Research, Elsevier Science \& Technology, $2^{\text {nd }}$ Edition.

[23] T. Lee Son, J. Wesson, and D. Vogts, (2018). Designing a Natural User Interface to Support Information Sharing among Co-Located Mobile Devices, South African Comput. J., vol. 30, no. 2, pp. 44-71.

[24] Rasmus Magnusson, (2020). High Confidence Network Predictions from Big Biological Data, PhD Thesis, Linkoping Studies in Science and Technology.

[25] Orfanou, K., Tselios, N., \& Katsanos, C. (2015). Perceived usability evaluation of learning management systems: Empirical evaluation of the System Usability Scale. The International Review of Research in Open and Distributed Learning, 16(2). DOI:10.19173/irrodl.v16i2.1955.

[26] Department of Statistics and Data Sciences, (2016). ANOVA and Post Hoc 2016," 2016.

[27] Chirayus, K., \& Nanthaamornphong, A. (2019). A systematic mapping review: Mobile user interface design guidelines for the elderly with cognitive impairments. In 2019 23rd International Computer Science and Engineering Conference (ICSEC) (pp. 35-42). IEEE. 